\title{
edCity - a New Learning Environment
}

\author{
Ken Fraser, \\ John Schostak, \\ City-plus network Manchester Metropolitan University \\ ken@city-plus.net_j.schostak@mmu.ac.uk
}

\begin{abstract}
edCity will facilitate learning anywhere, anytime, for anyone - for users of all ages both in traditionally taught and in pedagogically innovative courses - by fusing physical and virtual representations of real cities in order to provide a new learning framework.

The edCity project will be scenario-driven with major conceptual inputs to the design generated by highly interactive scenario-building activities.

After 18 months, a "Semantic Web" framework will be published and a prototype of the edCity application will be demonstrated. Tools will be developed to harvest and present learning content, generating multilingual, localised content modules accessible in the edCity environment. In years 2 and 3, the full edCity Learning Environment will be demonstrated in [at least] 2 European cities or regions and desk-validated in all 25 EU states.

edCity will be submitted as an FP6 Project. Research, development, deployment and management will involve 15 European organisations, from 8 EU states.
\end{abstract}

\section{Introduction}

"Learning is clearly a social, constructive phenomenon. It occurs as a side effect of interactions, conversations and enhanced presence in dynamic Virtual Communities". [1]

The purpose of edCity is to provide a new kind of learning environment to meet the needs of users from the whole range of communities, private and public sector organisations that together compose a city. As a virtual city, edCity is open to all users globally and allows them to create their own communities, organisations and associated learning environments. It interfaces with the realities of people's lives by drawing upon social, economic, political, cultural, library, academic data and services provided by the whole range of public and private sectors. Since access is anywhere, anytime, for any purpose, for anyone, its uses are limited only by the imagination within legitimate boundaries. Pedagogically, the framework is open to tailoring learning strategies and support to individual, group, organisational and system needs. It can be employed for fun and curiosity. It can be applied to real life decision making and action scenarios. Ed-city does not exclude any pedagogical or learning philosophy or strategy. It provides the resources for all. It will be as applicable for teaching a toddler to read and write as for a surgeon examining the options for a patient or an urban regeneration policy maker exploring the potential social, economic and cultural impact of a range of alternative development proposals on communities. Pedagogically, EdCity will itself learn the preferred learning strategies of its users.

\section{2. edCity - Background}

Many of the ideas now gaining currency in on-line education have been around several times before. Countries such as Finland saw very early that their survival as an economy in a globalising world was to be as a knowledge society (Framework Curriculum for the Comprehensive School 1994, Ministry of Education, Helsinki; Education, Training and Research in the Information Society: a national strategy 1995, Ministry of Education). Their strategy was to move away from a national curriculum to focus on the values and principles underpinning education in schools and communities which Schostak was involved in evaluating [6] (Norris et al 1995) and to integrate this across society through research (see also [5], Niemi 2003). Sadly, at the same time the UK and other countries were moving in the opposite direction! At the heart of the Finnish innovation was the understanding that the range of contemporary knowledge was too great to be encapsulated in a common core curriculum and the demands for creativity, innovation and skills meant that people had to become flexible problem solvers in order to work within complex, rapidly changing global environments. The old structures did not work, they believed, and thus new ones were sought. 
Something of this was expressed by Schostak [9] (1988) drawing upon his research on the impact of the new technologies in the UK throughout the 1980s:

The cultural richness of the world is immense. The computer, because of its networking capabilities, offers the curriculum developer gateways into an immense and open frontier of cultural experiences. Some will be fearful of this, wanting to close down possibilities in order to retain their own view of culture. Others will see it as an exciting change to explore and develop new ways of seeing and expressing experience in negotiation, or discussion, or dialogue, with their fellow explorers, both adults and children together. (Schostak p. 25)

Information technology provided the opportunity for interesting new infrastructures and models for learning. In particular it offered the opportunity of:

breaking into the hidden, controlling structures of schooling. "Hacking" [in an extended sense] is a metaphor here. By hacking into systems or programs, the hacker gains access to and is able to manipulate "private" information and program structures: hacking reveals the hidden. With access to knowledge, the hacker can act on (perhaps against) the hidden structures. (Schostak p. 4-5)

The notion of hacking into the curriculum and structures of schooling can be seen as a positive process. Indeed, it is a metaphor for the process by which an individual or a community agency may transform the curriculum for personal and community purposes: to gain 'ownership', to enliven, to generate the conditions for creativity and change. In short, to innovate. This possibility has recently been re-echoed by Hargreaves [4], (2003). There is thus an important question at the back of this renewed interest in information technology: why has there been so little impact on curriculum, pedagogy and school organisation over the last 20 years despite so much research and the recycling of enthusiasms and ideas concerning the importance of information technology?

For a range of answers to this, one can turn to the many sociological studies of the social functions of schooling that have been carried out and more particularly to the ways in which innovations have been implemented (c.f. [8], Pawson and Tilley 1997). Drawing upon these approaches Schostak [10] (2002) has described the design features appropriate to generate the conditions under which an innovation can be implemented. Briefly, this involves ensuring that the following key dimensions are appropriately aligned and mutually supportive:

a) The broad vision, values and philosophies that underpin a large scale project need to be fully debated and the implications for the different interest groups of a community drawn out and placed into dialogue so that some key practical agreements can be reached.

b) The mechanisms, procedures and cultural practices appropriate to the broad vision need to identified. Too often, new ideas are implemented employing old practices:, inappropriate mechanisms and procedures. Innovations typically have the effect of de-skilling people used to the old ways. Also, any innovation is likely to undermine vested interests that the old ways supported. Hence, change is likely to be blocked by those who have something to lose. In particular, what do teachers feel they might lose when confronted with the innovations of online education?

c) The resources, the material infrastructures necessary to underpin ideas and action have to be in place otherwise all will be in vain. Crudely, there is no point hoping for mass use of streaming video services if the connection levels to a school are insufficient to support simultaneous access by hundreds of children. Without the infrastructure the vision will never be achieved.

Innovations, if they fail, will fail because they have neglected one or more of these dimensions. Thus the following will sketch an approach - edCity - that attempts to ensure that each of the dimensions for embedding innovations is taken into account.

\section{3. ed-City Educational, Curricular, and Pedagogical Implications}

The following sub-sections raise a number of issues and questions to be explored. It is argued that the next generation technologies implicit in the ed-City concept will create the conditions for a qualitative leap, a paradigm shift in the provision of education. However, the seeds of this shift and the educational philosophies appropriate to it have already been articulated.

\subsection{Education, communities and intelligence}

In contemporary multicultural, multiethnic, multi-faith, multilingual societies what counts as a community? edCity explores this in relation to the new possibilities for communication, 'virtual meetings', 'chat rooms', and games that enable distributed networks of friends, people interested in similar topics and so on to develop communities of interest. An early focus on community and knowledge was put forward by Schostak [9] in terms of 'intelligence communities'.

Intelligence communities have always existed and are vital as tools for education and schooling. They are not the invention of the modern technologies. Nor are they idealistic deschooling conceptions. They are 
practical and already functioning groupings of enthusiasts and like-minded people. Individuals tend to seek out others, or associate with others having similar interests. In conversation (recall that one meaning of intelligence involves 'intercourse' or 'communication') they share views and criticise or explore the implications of certain views. In short, intelligence communities create intelligence, that is 'know-how', 'critical insight', 'informed opinion', 'intersubjectively validated facts', and other intelligent behaviours or products. ([9], Schostak 1988 p. 227)

A community of practice requires access to information of all kinds. However, intelligence and knowledge are more than just 'information'. Information has to be processed in various ways, critiqued and evaluated in relation to purposes. Thus:

Simple access to information is not enough. The part that educationalists can play is to provide resources for critical reflection and communicative action. This is where the deliberate recognition of and function of, intelligence communities is required. Schools as they presently exist can be redefined as resource centres providing centralised meeting places for individuals wishing to be placed into face-to-face contact with others sharing similar interests and concerns. ([9], Schostak p. 237)

The role of educationalists to support, facilitate and guide is critical but not sufficient. The new technologies cross the boundaries of time and place, enabling the formation of communities not necessarily founded on or limited to face-to-face, temporally fixed, geographically defined spaces. What are the new practices that need to be developed in order to work in these new environments? How, in short, can we build communities of practice appropriate to the opportunities afforded by the new technologies implicit in the concept of ed-City?

As one example of what may be done, Stephen Heppel at Ultralab has sited a 'school' in a shopping mall shop unit in Christchurch, New Zealand, supported by on-line technologies. It transforms the notion of 'school spaces', enables them to be flexibly and cheaply sited to meet changing needs and circumstances as well as integrating learning into the institutions of everyday life rather than separating them in specialised places. Furthermore, the more flexible, virtual and time-free that on-line educational services become the less we will feel the need to send thousands of children to schools at the same time each morning hence reducing the travel and congestion costs that we see repeated in every city and town of the world. The research question then is, how can cities be utilised more creatively in order to support ubiquitous, experiential and contextualised learning and virtual collaborative learning communities? edCity is such conceptual model an early example of which was developed by Schostak (2002) in collaboration with Ken Fraser of City-plus Network:

(http://www.enquirylearning.net/ELU/Issues/Information\%20Technology/HKtalk4.htm )

\subsection{Pedagogy, creativity and the curriculum}

Papert (1980:19) [7] wanted children to be 'the active builders of their own intellectual structures'. He developed technology-based educational approaches to support this. The philosophies and practices of educationists from, say Dewey (1938) [2] through to Stenhouse (1975) [12], and Freire (1970) [3] have with different emphases and purposes shifted the locus from teacher to learner. The developments that have led to the rapid increase of globalised information technologies, the Internet and its varieties of communities have in many ways echoed this shift. The implications for on-line curriculum development, teaching strategies and learning strategies are farreaching. How may curricula for diversity and the intelligence communities that emerge be supported through online communication infrastructures? What communities of practice need to be facilitated in order to produce and embed the conditions for the development of creativity?

\subsection{Continuous Professional Development as a way of embedding change}

Information technology and its gradual integration into the fabric of schools implies progressive innovations at a variety of levels. At a physical, architectural, level school buildings are slowly being transformed. Yet typically, when teachers think about giving lessons across a number of schools, their model is still that of the teacher at the front of the class leading a lesson, albeit using video conferencing techniques. How can we 'hack into' these traditional programmes in order to bring about new mechanisms, procedures and processes of schooling? There is now a wide acceptance among teachers that continuing professional development is required. Moreover, Action Research has been found by many schools to be a professionally acceptable way of encouraging teachers to think about and change their practices with regard to information technology. It would seem therefore that integrating CPD with whole school action research projects may be a way forward.

Action research has been employed as a vehicle for embedding and evaluating cultural change in many contexts and kinds of organisation. Somekh at MMU, for example, is currently being funded by the DfES (2003-06) to evaluate the ICT Test Bed Project. Its early results were to be published on the Becta website early in the 2004 academic year. Action research has been an important strand in this evaluation. Another project (The Pedagogy with E-Learning Resources Project), currently sponsored by the General Teaching Council for England, involves intensive action research in collaboration with four schools in Manchester and Bolton during the first two years. 
Teacher-researchers and pupil-researchers from these schools will work with the university-based researchers to lead work in up to 100 further schools during the third year. These and other projects have already developed expertise at embedding action research into the implementation and evaluation of innovations in the context of einitiatives. Such approaches need to be drawn more systematically into the whole project of bringing about the next generation of schooling integrated into on-line systems that have the kind of infrastructure described in 3 above (c.f. [5] Niemi 2003. This level of innovation based on leading edge broadband infrastructures (where gigabits/sec not megabits/sec are the connection rates available) has still not yet been tried despite the technologies having been commercially available for several years

\subsection{Cultural paradigms}

There are features of the Internet and its online communities which indicate the emergence of new cultural paradigms that are based on horizontal networks of association, peer-to-peer, point-to-point flows of information and communication that are neither time nor place dependent. The emergent feature of these networks is that they are self-organising rather than hierarchically designed and controlled. It is at the stage when the infrastructure impacts across communities and includes organisations other than schools (in the private, public and voluntary sectors) that the innovative aspects of the new technologies are most likely to be felt. A key research question is how they are to be integrated and managed and what will be the impact on schooling? This question will become all the more urgent as the kinds of infrastructure described below are embedded in national and international life with cultures forming on the basis of the kinds of connectivity that they sustain across time and place.

\subsection{The blurring of boundaries between school, home and their communities in the creation of the multiverses of edCity}

The blurring of boundaries has already been raised as between school, home and other institutions. However boundaries, geographically as well as in time, are erased. Within this context, the edCity project is directed at the creation of an advanced learning networked environment. edCity is a multiverse in the sense that it sustains the learning activities of individuals working alone, as well as a multiplicity of learning communities that emerge, evolve, exist for a time and then 'disappear' - to be replaced by other emergent communities of learning interest and activity. Like the games universes that create changing worlds within which players explore and are challenged, edCity is capable of drawing upon the information of cities to 'populate' the educational worlds of interest that learners define. Through semi-intelligent agents, it is able to draw upon available content, courses and course building tools to provide an environment populated with virtual 'intelligent' helpers, connecting with other people with similar interests as well as with those who provide pedagogic services. This infrastructure will naturally lead to evolving 'learning communities' that work within selected and customised learning environments. A given learning environment is capable of providing a range of learning tools, responding to particular learning styles, needs and interests. The learning environment that is generated itself 'learns' to adapt itself to the particular needs and interests of the learner.

\subsection{Problem solving and workplace learning}

Over the last decade, problem solving approaches to professional education and training have increased in popularity. In particular, edCity is conceived to be appropriate to workplace-based training and curricula which focus on the immediate or 'just in time' learning needs of professionals at every level in their careers from novice to expert (e.g., [13], Phillips et al 2000).

\section{4. edCity - Technology} shift.

This section identifies the logical and material infrastructures necessary to support the educational paradigm

The central Operational Objective is the implementation and demonstration of an advanced learning framework [the New Learning Environment - "edCity"] with content resources spanning a range of topics, deployed in two or more Cities/Regions.

To meet the research, scientific and technological objectives of being anywhere, anytime, for anyone, the vision must be supported with appropriate networked communications services to enable mobility and portability.

The project does not simply equate "learning" with "access to knowledge" but, to attain the learning vision of edCity, access and knowledge are indeed the key issues:

knowledge is famously unstructured and hence "difficult" - that is to say that it is hard work. The issue, then is "How far it is possible to manage the knowledge, relating resource retrieval dynamically to the learner's profile?"

access is not simply an open door - there is [generally] a corridor [or several] to be followed. The issues here are to navigate the labyrinth, to provide some keys and to present the required resources in an accessible form. 
edCity addresses these issues using a set of advanced techniques:

Knowledge management using semantic web [ontology] technologies:

Acquisition: "harvesting" data, including re-use of existing ["legacy"] content

Retrieval: intelligent selection of the harvested content

Knowledge access via two vectors:

Physical: High-performance multiservice networking and presentation - direct fibre, cable, high-speed DSL,

broadband wireless, free-space photonics, microwave links and a range of next-generation terminals;

Virtual: The New Learning Environment - "edCity" draws on interactive gaming and "virtual mall" techniques

to re-conceptualise the learning space.

The functional requirements identified above lead directly to the research agenda:

\section{Knowledge technologies}

Knowledge harvesting and retrieval and course building

Physical access: communications and devices

Virtual access: the New Learning Environment, "edCity"

\subsection{Knowledge technologies}

"The vision of the Semantic Web aims at creating a Web where information can be "understood" by machines as well as by humans" [http://www.ontoknowledge.org/oil - the OIL initiative was funded under the On-To-Knowledge project (IST-1999-1013) and IBROW (IST-1999-19005)].

To facilitate the specific RTD actions below, it will be necessary for the RTD partners to conduct a rapid but thorough review of a number of relevant technologies, to evaluate their relevance to PLURAL and to recommend their adoption, rejection or enhancement.

Specifically, at least the following will be analysed:

DAML

OWL

Dublin Core Metadata

MPEG7, MPEG21

RDF and RDFS

OIL

WARM

OKBC

XOL

The edCity implementation task will require the marrying of multi-agent simulation techniques [e.g. Swarm] to the ontology-driven applications. This in turn will require the deployment of an agent expression language [e.g. DAML].

edCity execution will require advanced user session management [e.g. Cocoon, JSP].

The Knowledge Technology review will yield specific recommendations concerning Standards and Tools.

\subsection{Knowledge harvesting and retrieval and course building}

The ontology techniques which characterise the semantic web vision have to be applied both to new and to "legacy" content.

Actual application of proposals like OIL, RDFS, OKBC and XOL to real content will inevitably raise significant functionality issues [see, for example, http://www.tzi.de/ heiner/public/ECAl-00ws.pdf] and extensions to these proposals will be required, generating contributions to actual or emergent standards. Resolution of the anticipated functionality problems will almost certainly require development of [1] "purist" tools to process new content and [2] "realist" tools to refine existing RDFS/metadata.

This activity will yield a set of harvesting and course-builder tools.

\subsection{Physical access: communications and devices}

It will be a pre-condition for operation of the edCity environment that high-performance, multiservice networks exist to support the end-users.

Some of the envisaged scenarios are likely to require communications services to end-users at better than 10 Mbits/sec [i.e. better than fast Ethernet speeds] so typical current "consumer" end-user services [e.g. xDSL, cable, satellite] will not suffice. Against this requirement, currently, fibre-to-the-building and fixed broadband wireless are candidate technologies for discrete sites and free-space photonics is a potentially mould-breaking, emergent technology. Within building or campus-scale groups, available LAN and WLAN technologies should suffice, provided that the upstream bandwidth is adequate for the aggregated demand.

At the service level, it will be highly desirable, at least for some of the scenarios, that the end-user experience comprise seamlessly integrated data, streaming video and streaming audio channels. "Everything-over-IP" may not be an optimal solution here, although commercial and procurement issues may constrain deployment in this context. When [and only when] these demanding "terminal" requirements have been specified, it will be advantageous to involve major vendors in this sector [e.g. Nokia, Ericsson, Motorola, Sony], in the post-project exploitation stage. 
In the "IP" area, the design will ensure implementation over IPv6, noting in particular the impact of muchimproved multicast capability.

Truly ubiquitous access will require that versions of edCity be operable on a wide range of device types - not merely standard PCs or Macs. Notably, support should be available for handheld devices [Personal Digital Assistants and their successors] and progressively more sophisticated cellphone/mobile devices, as well as evolved interactive TV [iTV] systems.

It may be difficult, in terms of time, commitment and budget, to realise the full stack of services which should be available to support the target scenarios and end-user systems. In one case, however, this may be possible, since a new community-scale network is emergent in Norwich, Norfolk [UK Eastern region].

This activity will yield specifications for multiple solutions capable of supporting edCity usage.

\subsection{Virtual access: the New Learning Environment, "edCity"}

The most visible project outcome will be a New Learning Environment - "edCity". The detailed design of edCity will be determined largely by the iterative "Scenarios" effort but it is evident that it will draw heavily on commercial "games" experience, including simulation, virtual reality [VR] and avatar techniques.

This activity will yield first a prototype edCity product and subsequently one or more enhanced versions based on deployment experience.

\section{References}

[1] ELeGI website, http://www.elegi.org.

[2] Dewey, J. (1938) Experience and Education, New York, Collier.

[3] Freire, P. (1970) Cultural Action for Freedom, Harmondsworth, Penguin.

[4] Hargreaves, D. H. (2003). Education Epidemic: Transforming Secondary Schools Through Innovation Networks. London: Demos.

[5] Niemi, H. (2003) 'Towards a Learning Society in Finland: information and communications technology in teacher education', Technology, Pedagogy and Education, Vol. 12, No, 1., 85-103.

[6] Norris, N., Aspland, R., McDonald, B., Schostak, J.F. \& Zamorski, B. (1995) An Independent Evaluation of Comprehensive Curriculum Reform in Finland, CARE, UEA; Finnish Board of Education.

[7] Papert, S. (1980) Mindstorms: children, computers and powerful ideas, New York: Basic Books; Brighton: Harvester.

[8] Pawson, R., and Tilley, N. (1997) Realistic Evaluation, London; Thousand Oaks, California: Sage.

[9] Schostak, J. F. (ed.) (1988) Breaking into the Curriculum: the impact of information technology on schooling, London, New York. Methuen.

[10] Schostak, J.F. (2002) Understanding, Designing and Conducting Qualitative Research in Education. Framing the Project. Open University Press.

[11] Schostak, J. F. (2002) 'The globalisation of Education - what are the challenges?', Information Technology Strategy Committee Seminar Series, Hong Kong Institute of Education.

[12] Stenhouse, L. (1975) An Introduction to Curriculum Research and Development, London: Heinemann.

[13] Phillips, T. P., Schostak, J. F., and Tyler, J. (2000) Practice and Assessment in Nursing and Midwifery: doing it for real, Research Reports Series No. 16, London, ENB.

Keywords: learning, scenario, semantic web, city

Contacts: $\quad$ Mr K C Fraser

City-plus network

18 Watlings Court

Cow Hill

Norwich NR2 $1 \mathrm{HA}$

United Kingdom

ken@city-plus.net

\author{
Professor J. Schostak \\ Education and Social Research Institute \\ Institute of Education \\ Manchester Metropolitan University \\ 799 Wilmslow Road \\ Didsbury \\ Manchester M20 2RR \\ United Kingdom \\ j.schostak@mmu.ac.uk
}

